In Eq. (5), $v_{B}$ and $k_{s}^{\prime}$ are invariable while $\rho_{B}$ takes distinct values for different mixtures. Hence, according to Eq. (5), surface rate constant $k_{s}$ should vary corresponding to the molar density of $\mathrm{B}$ in each particle. With insertion of Eq. (5), Eq. (4) is therefore rewritten as

$$
\tau=\frac{R}{b \bar{k}_{s}^{\prime} v_{B} C_{A 0}}
$$

This is now independent of the particle molar density of $\mathrm{B}$, as is seen in experimental observations. Consequently, one may understand that the rate constant $k_{s}^{\prime}$ based on the effective surface area given by Eq. (5) must be used instead of $k_{s}$ based on the geometrical surface area in representing the rate equation for a solid reactant in the mixture with an inert.

\section{Nomenclature}

$C_{A 0}=$ concentration of $\mathrm{A}$ in bulk phase $\quad\left[\mathrm{mol} / \mathrm{m}^{3}\right]$

$k_{\mathrm{s}}=$ apparent surface rate constant $\quad[\mathrm{m} / \mathrm{min}]$

$\begin{array}{llr}k_{s}^{\prime} & =\text { rate constant based on unit area of } \\ & \text { effective surface } & {[\mathrm{m} / \mathrm{min}]} \\ R & =\text { radius of a particle } & {[\mathrm{m}]} \\ r_{C} & =\text { radius of an unreacted core } & {[\mathrm{m}]} \\ t & =\text { reaction time } & {[\mathrm{min}]} \\ v_{B} & =\text { molar volume of B } & {\left[\mathrm{m}^{3} / \mathrm{mol}\right]} \\ X_{B} & =\text { extent of conversion of B in a particle } & {[-]} \\ \rho_{B} & =\text { molar density of B in a particle } & {\left[\mathrm{mol} / \mathrm{m}^{3}\right]} \\ \tau & =\text { complete reaction time of a particle } & {[\mathrm{min}]}\end{array}$

\section{Literature Cited}

1) Farrior, W. L., A. M. Poston, and E. C. Oldaker: Preprint for the 4th Energy Resources Conference, Kentucky 1976.

2) Levenspiel, O.: "Chemical Reaction Engineering", John Wiley, N.Y. (1972).

3) Seth, B. B. L. and H. U. Ross: Trans. Met. Soc. AIME, 233, 180 (1965).

4) Westmoreland, P. R. and D. P. Harrison: Environ. Sci. Technol., 10, 659 (1976).

(Presented at the 45th Annual Meeting of The Soc. of Chem. Engrs., Japan, Osaka (1980).)

\title{
RESPONSE OF CIGARETTE SMOKE PARTICLES TO CHANGE IN HUMIDITY
}

\author{
YASUO KOUSAKA, KIKUO OKUYAMA AND CHIU-SEN WANG \\ Department of Chemical Engineering, University of Osaka Prefecture, Sakai 591
}

Do particles in cigarette smoke grow larger in humid air? Results of our study indicate that condensation of water vapor on cigarette smoke particles takes place only under supersaturation conditions.

Size distributions of smoke particles generated with filters (Wakaba brand, the Japan Tobacco and Salt Public Corporation) were measured by the apparatus shown in Fig. 1. The experimental set-up consisted mainly of an ultramicroscopic sedimentation size analyser"), a smoking device, two humidifiers and a psychrometer. Each humidifier consisted of a silica gel bed, a bubbler, and two control valves. The relative humidity of the air stream from each humidifier was controlled by adjusting the flow rates of the air streams through the bubbler and the silica gel bed. Supersaturation conditions can be obtained by heating the water in the bubblers ${ }^{5}$.

The apparatus was first tested by experiments with sodium chloride particles, generated by atomizing saline solutions and subsequently drying the droplets

Received $J_{u l y} 3,1981$. Correspondence concerning this article should be addressed to $Y$. Kousaka. Chiu-sen Wang is now at Department of Chemical Engineering and Materials Science, Syracuse University, Syracuse, New York 13210 USA in a silica gel bed (not shown in Fig. 1). Figure 2 shows the measured geometric mean diameter (number median diameter) of $\mathrm{NaCl}$ particles as a function of relative humidity at $25^{\circ} \mathrm{C}$. The results indicate that $\mathrm{NaCl}$ particles have a deliquescent point at about $76 \%$ relative humidity, which is in agreement with the value reported in the literature (see, for example, (2)).

Particles in cigarette smoke can grow by either Brownian coagulation $^{31}$ or condensation. To mini-

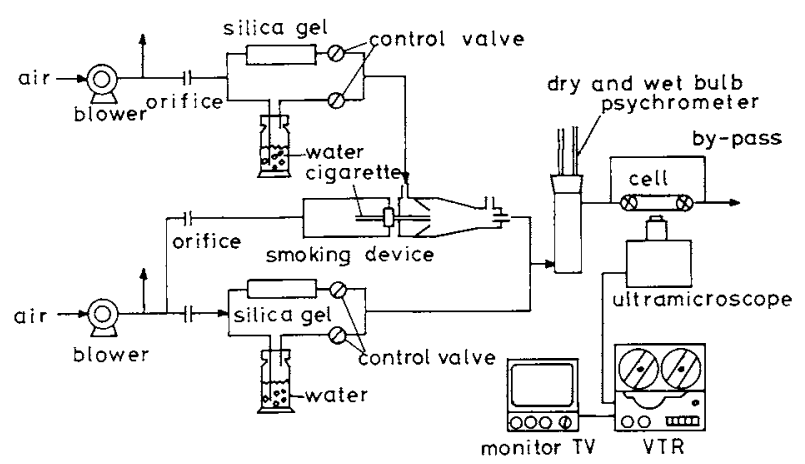

Fig. 1 Experimental apparatus 


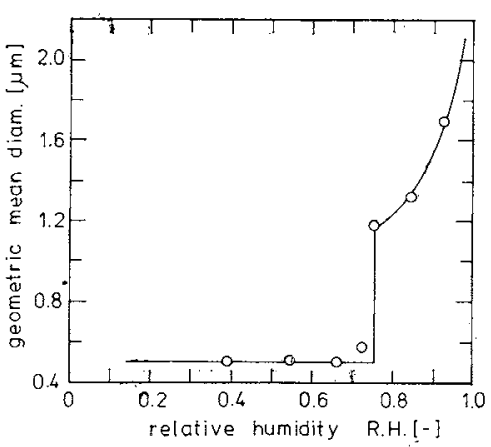

Fig. 2 Relation between geometric mean diameter of $\mathrm{NaCl}$ particles and relative humidity

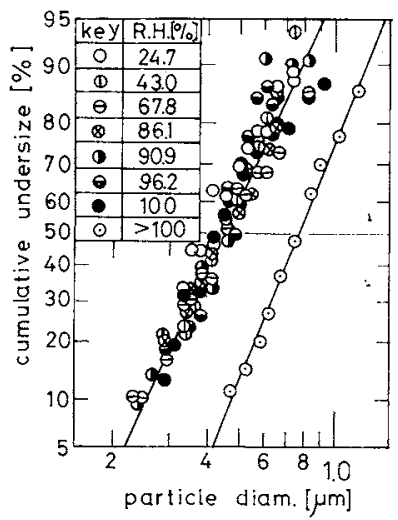

Fig. 3 Particle size distribution of cigarette smoke at various relative humidities

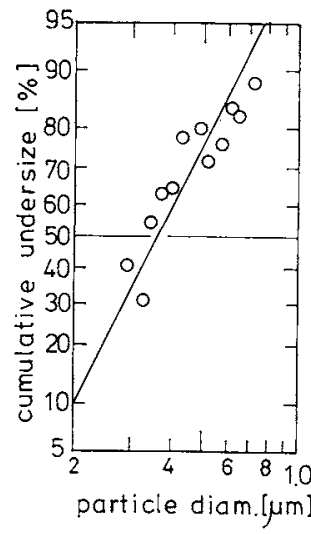

Fig. 4 Particle size distribution of exhaled cigarette smoke

mize the effect of coagulation, the cigarette smoke was diluted about 100 -fold by filtered, humid air. The diluted smoke contained approximately $10^{6}$ par- ticles $/ \mathrm{cm}^{3}$.

Figure 3 shows the measured size distributions of cigarette smoke particles at various relative humidities at $25^{\circ} \mathrm{C}$ and one supersaturation condition (the degree of supersaturation was not determined). The residence time of particles in the experimental system ranged from 10 to 30 seconds. Although marked increase in particle size took place under supersaturation conditions, no appreciable growth was seen at $100 \%$ or lower relative humidities. Under subsaturation and saturation conditions, the number median diameter of the $\log$ normally distributed particles is $0.44 \mu \mathrm{m}$. Carter and Hasegawa ${ }^{1)}$ reported a mean diameter of $0.4616 \mu \mathrm{m}$ for particles generated from cigarettes with a conventional filter, but did not state the relative humidity.

Figure 4 shows the measured size distribution of particles exhaled from a human subject, following inhalation of cigarette smoke. The smoke was diluted about 100 -fold before inhalation. The size distribution of exhaled particles differs only slightly from those shown in Fig. 3 for relative humidities up to $100 \%$.

It is concluded, therefore, that the change in size of cigarette smoke particles in the respiratory system is caused mainly by Brownian coagulation and, possibly, by condensation of water vapor under supersaturation conditions, which may be induced by a drop in temperature of inhaled smoke.

\section{Acknowledgments}

This study was part of the Japan-U.S. Cooperative Science Program, supported in part by the Japan Society for the Promotion of Science Grant No. ENGR-021 and by the U.S. National Science Foundation Grant No. INT-7821376. K. Mizuta was very helpful in experimental work.

\section{Literature Cited}

1) Carter, W. L. and I. Hasegawa: J. Colloid Interface Sci., 53, 134 (1975).

2) Junge, C. E.: "Air Chemistry and Radioactivity", p. 133, Academic Press, New York (1963).

3) Keith, C. H. and J. C. Derrick: J. Colloid Sci., 15, 340 (1960).

4) Yoshida, T., Y. Kousaka and K. Okuyama: Ind. Eng. Chem., Fundam., 14, 47 (1975).

5) idem: ibid., 15, 37 (1976). 